\title{
Adherence to antiretroviral therapies in people with HIV infection: a qualitative approach from a narrative-based medicine study A Tomasini*1, R Murri², G Guaraldi ${ }^{3}$, N Squillace ${ }^{3}$, G Orlando ${ }^{3}$, S Zona ${ }^{3}$, I Mazeu $^{3}$, MS Aloisi ${ }^{1}$ and M Bossola ${ }^{2}$
}

\begin{abstract}
Address: ${ }^{1}$ Koimed, Rome, Italy, ${ }^{2}$ Catholic University of Sacred Heart, Rome, Italy and ${ }^{3}$ Univeristy of Modena and Reggio Emilia, Modena, Italy
\end{abstract}
* Corresponding author

\author{
from Ninth International Congress on Drug Therapy in HIV Infection \\ Glasgow, UK. 9-13 November 2008 \\ Published: 10 November 2008 \\ Journal of the International AIDS Society 2008, I I (SuppI I):PI77 doi:I0.II86/I758-2652-I I-SI-PI77
}

This abstract is available from: http://www.jiasociety.org/content/I I/SI/PI77

(c) 2008 Tomasini et al; licensee BioMed Central Ltd.

\section{Purpose of the study}

Antiretroviral therapies significantly improved morbidity and mortality of HIV-infected people. However, regimens are complex to be taken and in the last years adherence to drugs has been raised as a crucial factor for therapeutical efficacy. The narrative medicine is a developing approach to complement information obtained by traditional measures on health status. Our objective has been to investigate through the narrative-based medicine approach patterns of non-adherence and reasons for suboptimal adherence. This information may help to design intervention strategies aimed to improve adherence to antiretroviral drugs.

\section{Methods}

A semi-structured interview to be video-taped was proposed to consecutive patients with HIV attending Italian clinical centers. A text analysis was performed using the ATLAS-ti software.

\section{Summary of results}

Twelve people with HIV were interviewed (four females). All interviewed people were taking HAART. Age range: 38-65 years. Twenty-two hours of interviews were obtained.

Adherence to drugs was often reported as the crucial problem in the daily management of the HIV infection. Among reasons for suboptimal adherence several concepts were elucidated through the interviews: 1) adverse events related to therapy are the main cause of suboptimal adherence; 2) particularly, alterations of body aspect due to abnormal adipose tissue redistribution (so-called lipodystrophy) were identified as a strong factor leading to suboptimal adherence; 3 ) reduction or modification of daily dosage of antiretroviral drugs were reported very frequently (11/12 interviewed people, $91.6 \%)$. They were often done without informing the physician. The main reason for doing a reduction or modification of daily dosage was an adverse event. People often believe that physicians could not be aware of these modifications since no immediate change in viral load is detectable; 4) suboptimal adherence to drugs was correlated to a poor belief in drug efficacy; 5) the social representation of the drug often influences adherence; and 6) the drug experience often is a reminder of the psychological experience of the illness.

\section{Conclusion}

Information obtained through a narrative-based medicine approach is a useful instrument to identify strategies for the improvement of adherence to drugs, and ultimately for the efficacy of treatment in people with HIV. The content of interview also offered complementary information that can positively support an empathic patient-physician communication. 